\title{
Mito y Escritura en Don Segundo Sombra
}

La tradición narrativa del enmarcamiento se practica en los capítulos 12 y 21 de Don Segundo Sombra. Estos sólo han merecido breve y en general reciente atención de la crítica.

He de centrar mi enfoque en el cap. 21.

Raúl Moglia en 1928 lo comparó con "El soldado y la muerte", un cuento popular ruso. Moglia aplicó para ello algunos criterios formalistas, muy elementales, y afirmó que Güiraldes habìa recogido su material de la tradición oral.1

Giovanni Previtali sostiene que el del cap. 21 es un cuento moralizador de intención humorística y lo conecta con la leyenda fáustica, a la que ve acuñada en un molde regional. ${ }^{2}$

Mireya Camurati afirma que la intención de Güiraldes fue: “a) Ofrecer cuadros de sabor local o costumbrista. b) Organizar la narración, modificando el ritmo y distrayendo el tiempo narrativo. c) Completar la imagen del personaje. d) Comprometer al lector con la obra al crear, entre éste y la ficción, un plano intermedio: el de la ficción dentro de la ficción, donde personajes y lector son igualmente oyentes de la historia."3

Camurati, asimismo, pone de relieve que se han recogido versiones folklóricas del relato en Argentina, España, Chile, Puerto Rico y México. 4

En verdad, el tema de la historia narrada en el cap. 21, es decir la del herrero y el diablo, corresponde al tipo 330 del cuento folklórico en la clasificación de Antti Aarne y Stith Thompson ${ }^{5}$ y de él se conocen 146 versiones finlandesas, 54 de Estonia, 71 danesas, 359 de Irlanda, 90 francesas. . . 
Partiendo del resumen hecho en dicha tipología, Donald McGrady, repara en que el único cambio importante introducido por Güiraldes se da en la alteración de los motivos I y II (Contrato con el Demonio, Recepción de objetos mágicos) y que la narración de Don Segundo incorpora ciertos pormenores que reflejan la vida del gaucho y su modo de describir la realidad. Piensa McGrady que Güiraldes habría reproducido con solo variaciones de detalle alguna versión oral del cuento. 6

Evelio Echevarrìa recientemente se preocupó por la inserción del cuento en la novela. Piensa que hay general acuerdo en considerarlo ajeno a la trama de la novela o de importancia minima dentro de ésta pero rechaza tal idea, y adhiere a la opinión de Juan Carlos Ghiano según la cual Don Segundo acudía a la conseja tradicional "para dar una lección de múltiples aplicaciones."7

Echevarría ve al cap. 21 deliberadamente incluído en la novela, con función específica y conectado a las desventuras de Fabio en los dos precedentes a través de la pudorosa y oblicua justificación del propósito moral de su cuento que enuncia el propio narrador ("-Te vi a contar un cuento, para que se lo repitas a algún amigo cuando éste ande en la mala"). Echevarrïa lo ve ligado a la trama "con un claro mensaje de consuelo, resignación y estímulo" y como refuerzo de la unidad de la novela y de la representación de un gaucho ideal practicada por el novelista. 8

Por nuestra parte queremos subrayar que frente a la pluralidad de versiones del tipo 330 Aarne-Thompson está vacante el examen de a cuál de ellas se ajustaría con más proximidad la escritura practicada por Güiraldes, aunque no es a un cotejo de tal naturaleza adonde nos dirigimos.

Incluso si el novelista hubiese sido mero transcriptor de un texto anónimo, los mecanismos de selección que han operado en la adopción del texto y en el rechazo de sus similares, y -fundamentalmente- en la adopción del tipo 330 y no de otros, suponen, como toda elección dentro de una serie, un acto de voluntad positiva y cierto número de negaciones, con carga estilǐstica y eficacia creadora.

Visto así, el acto de selección no sólo corresponde a las virtualidades inscriptas en el objeto elegido sino también -y especialmente- a las notas particulares en el selector que le hacen apto para leer aquellas virtualidades y descontextar de su serie al objeto de elección.

Comenzaremos pues por el examen del objeto elegido.

Tanto en el resumen de Aarne-Thompson como en el capítulo 21 hay cuatro elementos reconocibles: la recepción de gracias u ob- 
jetos mágicos con sentido de gracias; el contrato con el Demonio; el engaño al Demonio; la expulsión del Infierno y del Cielo.

La recepción de objetos mágicos se encuadra en una visita que Jesucristo (o San Pedro) hace al herrador y durante la cual le concede tres gracias: un árbol que retiene "como pegada" a la gente que trepa a él, un banco con el mismo poder respecto de quienes lo usan, una mochila que fuerza a la gente a entrar en ella.

Algunas historias recogidas en su célebre colección por los hermanos Grimm ofrecen notable parentesco con el 330 AarneThompson y el cap. 21 de Güiraldes. Asì ocurre con "El hombre pobre y el hombre rico", cuento 87 de dicha colección: en éste, el Señor bajo apariencia de un vagabundo, pide hospitalidad al rico del lugar y le es negada. Un pobre vecino, en cambio, le trata muy bien y es premiado con tres gracias que usa inteligentemente. El rico también obtendrá tres gracias, pero se servirá de ellas con ridícula torpeza.

Complementario de este cuento es el número 81, "Hermano Lustig" en el que en torno de San Pedro disfrazado de mendigo y de un soldado que vuelve de la guerra, se teje una compleja historia a la que corona la presencia de una mochila que fuerza a la gente a entrar en ella. Castigo de demonios sobre un yunque y expulsión del Infierno y del Cielo se muestran en el final de la anécdota que se cierra de modo inesperado.

También complementario es el 147, "El viejo hecho joven" que muestra al Señor y a San Pedro caminando por la tierra y recibiendo la hospitalidad de un herrero.

Motivos correspondientes al tipo 330 Aarne-Thompson son reconocibles en Grimm 81, 87 y 147. Tales motivos, combinados, podrǐan cubrir casi integramente el tipo mencionado.

Cabe aquï una reflexión sobre el cuento folklórico en su relación con el mito. Es dicho cuento forma de entretener cuyo éxito es medido por el entretenimiento que proporciona, y se produce en tiem po y geografía determinados: en instancia última, es producto artístico. Todas estas notas diferencian esencialmente al cuento folklórico del mito, pero no impiden que se practique una lectura mitológica, o si preferimos el vocablo, mitográfica de aquél.

Son susceptibles de tal lectura los textos ya señalados en la colección Grimm, particularmente el 87, "El hombre pobre y el hombre rico".

En un comentario al trabajo de los hermanos Grimm, Joseph Campbell escruta los principios de artesanía que dieron forma a los 
cuentos folklóricos, es decir a un arte que logró revelar a través de cosas mortales el brillo de formas eternas. Halla en estas obras "precisión espiritual" y califica a su poder de "maravilla instructiva" ("Instructive wonder"). Subraya Campbell que pueblos del tipo premoderno dieron por sentado el funcionamiento de una energìa trascendente en las formas de espacio y tiempo y que, por tanto, a todo artista le era exigido que su producto mostrara el signo del espiritu mientras servila a su fin mecánico. Y concluye: "The function of the craft of the tale, therefore, was not simply to fill the vacant hour, but to fill it with symbolic fare. And since symbolization is the characteristic pleasure of the human mind, the fascination of the tale increased in proportion to the richness of its symbolic content".

Si preguntamos a la mitología por la carga simbólica soterrada en el 330 Aarne-Thompson, y en las parciales hipóstasis de éste recogidas por los Grimm, podríamos verlo como una versión irónica del mito de Filemón y Baucis.

Este mito se contiene, como es sabido, entre los versos 610 y 715 del octavo libro de las Metamorfosis de Ovidio, al menos en su más recurrida versión, siendo las Metamorfosis, como bien anota Frank Justus Miller en su edición, un manual de mitología clásica y la más importante fuente de saber mítico para todos los escritores que sucedieron a su autor. 10

Según Ovidio, Zeus acompañado de Hermes, visitaba la tierra bajo forma humana; fatigados, buscaron refugio para la noche, pero todos les cerraron sus puertas excepto una pareja de ancianos, Filemón y Baucis, quienes les dieron hospitalidad. Antes de partir, los dioses revelaron su identidad e invitaron a sus huéspedes a que los siguieran hasta la cima de una montaña. Zeus y Hermes castigarán a la región inundándola y premiarán con graciosas concesiones a Filemón y a Baucis.

La historia, de probable origen frigio, enfatiza el sagrado deber de la hospitalidad y reúne dos leyendas de amplia circulación: la que muestra a dioses disfrazados que premian la hospitalidad y castigan la falta de ella y la que se refiere a ciertos individuos preservados de la inundación como premio a su piedad. 11

La primera de ellas ("dioses disfrazados. ..") es catalogada bajo la indicación Q1.1 y correlativas por Stith Thompson en su MotifIndex of Folk Literature donde se anotan entre otras las versiones coleccionadas por Espinosa en el dominio lingüistico español y algunas recogidas en India y en Japón. 12 
A esta altura de nuestro razonamiento es lícito indagar cuáles fueron las primeras exposiciones de Güiraldes a textos conformados sobre el 330 Aarne-Thompson, o a versiones del mito que constituye su carga simbólica. Y tal indagación tiene como meta establecer la presencia de una huella psicológica, infanto-juvenil, determinante de sus operaciones de selector en el caso del capítulo 21.

Como paso previo, conviene señalar algunos canales a través de los cuales el mito fue recibido, de manera vicaria, por las audiencias cultas europeas e hispanoamericanas.

La vitalidad del mito está eficazmente registrada en el Lexikon de Hunger ${ }^{13}$ y en las investigaciones de Beller ${ }^{14}$. Filemón y Baucis, entre otras cosas, dieron nombre y asunto a óperas de Gluck (1769), Haydn (1773) y Gounoud (1860) y a pinturas de Rubens (1620) y Rembrandt (1658). En su torno bordó La Fontaine una extensa fábula y es de conocimiento general en Francia la historia de "Les trois souhaits", versión folklórica del mismo asunto. Filemón y su mujer también ocupan las dos escenas iniciales del quinto acto del segundo Fausto. 15

Y no debe olvidarse que el mito, en sus fuentes clásicas, no sólo está a disposición de los lectores de Ovidio, sino que puede hallárselo en Lactancio, y en los fabulistas Aviano y Fedro ${ }^{16}$.

Si nos preguntamos ahora por las vías a través de las cuales el mito de Filemón llegó a establecer una precoz huella psicológica en el novelista sudamericano, será juicioso acudir, en primer término, a su carta autobiográfica a Guillermo de Torre. Allì dice Güiraldes, respecto de sus años infantiles:

Mis padres fueron a Europa cuando yo tenïa un año y pasaron allî cuatro. Volví hablando francés y alemán. Este último idioma presenció mis aficiones al libro. Usted que tanto conoce, sabrá la importante biblioteca que puede tener un chico alemán. Sabỉa de memoria Max und Moritz. Leỉa los cuentos de los Brïder Grimm, los Andersen Märchen, miles de historias de aventuras en la India, Africa, América. Recuerdo Mali der Schangenbändegir, Durch Urwald und Wustensand, Im Goldland Kaliformia..., etc. Un héroe de novela americana se llamaba Lederstrumf, lo que quiere decir media de cuero. Recién hace poco me he dado cuenta que esa media de cuero debía ser la bota de potro ${ }^{17}$. 
Pese a lo aquí testimoniado, y aunque queda razonablemente en claro el predominio de la hipótesis Grimm, no debe descartarse la posibilidad de una múltiple exposición del escritor en función de las coordenadas culturales de su época. No estaría demás recordar la eficacia de los estudios clásicos y franceses en el colegio Lacordaire y en el Instituto Libre de Segunda Enseñanza, donde acudió Güiraldes como alumno, y en los cuales la traducción de Fedro, el aprendizaje par coeur de largas tiradas de La Fontaine y la lectura de fragmentos de escritores romanos en su lengua original eran parte de la rutina que se imponỉa a los escolares. Y ¿podrá acaso pensarse que haya pasado por alto Güiraldes, aunque más no sea que por gauchescas razones, la lectura del Fausto alemán? O que se haya sustraído a las versiones líricas del mito, al menos en la edad adulta, teniendo en cuenta su marcado interés por la música y el canto, el que le llevara en Parìs a frecuentar a Stravinsky y Falla, a Jane Bathori y Ninon Vallin, a María Barrientos y Ricardo Viñes 18.

¿Quién podía ignorar en su época la romanza de Baucis "Philémon m'aimerait encore", o el encantador dúo "Du repos voici l'heure', o los populares couplets de Vulcano, de la ópera de Gounod?

Todo se dice atendiendo a la idea de que la "simpatía" de Güiraldes por el cuento folklórico cuya escritura da sustancia al capítulo 21 , tiene sus raíces en experiencias previas de variada e intensa tonalidad que operaron en el selector cuando fue expuesto a la serie portadora del objeto elegido.

Estimamos que aquil debiera terminar nuestro informe si no fuese Güiraldes el autor de $E l$ sendero, el Teósofo que con un pie en el lado de la muerte aún tenía tiempo de acudir a conferencias de Jinarajadasa; el que al final de su vida admite haber tenido experiencias misticas $^{19}$.

Desde esta perspectiva, Don Segundo plantea la posibilidad de una lectura espiritualista dentro de la cual la inclusión del 330 Aarne-Thompson, sin desvirtuar el propósito moral detectado por Ghiano y Echevarrìa, se enriquecerìa de virtualidades simbólicas 20 .

Al respecto merece recordarse que Jakob Grimm en su Mitologia germánica intenta penetrar en la naturaleza de los mitos de Noé. Deucalión y Filemón, entre otros, insertándolos en una visión general del gran mito del Diluvio 21 . El dato interesa aún más si tenemos presente que esta obra capital de Jakob y la colección de Märchen se reflejan entre sí especularmente de tal manera que lo que aquélla examina como mito lo tiene ésta como cuento folklórico. 
Lo que intentara Jakob Grimm se hace más neto y preciso en la revisión del mito de Filemón practicada por Malten 22 , y se propone en rigurosos términos comparatistas en las investigaciones de Joseph Fontenrose 23 .

A esta altura del conocimiento del tema, es aceptado que la única versión existente del mito frigio del Diluvio, la historia de Filemón y Baucis, emparentaría con el gran mito babilonio-sumerio del Diluvio, del cual la historia de Utnapishtim en Mesopotamia, la historia de Noé entre los hebreos y la historia de Deucalión en Grecia serǐan sus variantes.

Entre las conclusiones a las que llega Fontenrose hay algunas particularmente sugestivas, las siguientes: que las historias de Filemón y Lot son variantes del mismo tipo de historia y ésta un subtipo del mito babilonio del Diluvio; que la historia de Lycaón es una variante del subtipo Lot, y que ninguna distinción útil puede ser hecha entre las historias de diluvios locales y las historias de diluvios universales $^{24}$.

Si el 330 Aarne es versión irónica del mito de Filemón y Baucis y éste a su vez se inserta en el gran mito babilonio-sumerio del Diluvio, es pertinente preguntarnos por la eventual significación espiritualista de la narración practicada por el resero Gurú al Chela. Más pertinente aún si recordamos que de acuerdo con una tradición clásica, Sísifo aprisionó a la Muerte cuando ésta vino por él con lo que nadie murió hasta que Ares libertó a la muerte 25 .

Y como final consideración no está de más recordar la presencia del 330 Aarne en India y Japón, documentada por Thompson ${ }^{26}$, y que los capítulos donde narra Don Segundo son el 12 y el 21, números místicos múltiplos de 3 .

Quede el 21 asediado y desafiante en su eficacia de problema.

Brooklyn College \& Graduate Center CUNY

ALBERTO BLASI

\section{NOTAS}

1. "Un cuento de Don Segundo Sombra y un cuento popular ruso," Nosotros, 63 (oct. 1928), pp. 113-14.

2. Ricardo Güiraldes and Don Segundo Sombra: Life and Works (New York: Hispanic Institute in the United States, 1963), pp. 145-47.

3. "Función literaria del cuento intercalado en Don Segundo Sombra, La vorágine y Cantaclaro," Revista Iberoamericana, 39 (1971), pp. 403-08, 416-17. 
4. Ibid., p. 407.

5. The Types of the Folk-Tale: A Classification and Bibliography, FF Communications, No. 74 (Helsinki: Academia Scientiarum Fennica, 1928).

6. "Un cuento folclórico en Güiraldes y Carrasquilla," Thesaurus, 26 (1971), pp. 143-46.

7. Ghiano, Ricardo Güiraldes (Buenos Aires: Pleamar, 1966), p. 107.

8. "Función de los cuentos de Don Segundo Sombra," Romance Notes, 16 (Autumn 1974), pp. 232-35.

9. Grimm's Fairy Tales, complete ed. (rpt. New York: Pantheon Books, 1944), p. 862.

10. Ovid, Metamorphoses, trans. F.J. Miller (Cambridge, Mass.: Harvard University Press, and London: William Heinemann Ltd, 1966), I, pref.

11. "Philemon and Baucis," Encyclopaedia Britannica, 1910-11.

12. Bloomington and London: Indiana University Press, 1966.

13. Herbert Hunger, Lexikon der Griechischen und Römischen Mythologie, 5a. ed. (Wien: Verlag Brüder Hollinek), pp. 284-85.

14. "Philemon und Baucis," Brockhaus Enzyklopädie, 1972.

15. La Fontaine, "Philémon et Baucis"' XII. 25; interesante ver Hechos XIV.pp. 8-15.

16. Lactantius, Divinae Institutiones VIII. 7-9; Phaedrus, append. fab. 3; Avianus, fab. 22.

17. Obras completas (Buenos Aires: Emecé, 1962), p. 27. set. 1950.

18. Angel J. Battistessa, "Don Segundo Sombra en Parìs," La Nación, 10

19. Güiraldes, Ob. comp. ya cit., p. 544.

20. Como mensaje de Gurú a Chela.

21. Teutonic Mythology, trans. James Steven Stallybrass (London: George Bell \& Sons, 1883), II, pp. 576-81.

22. L. Malten, in Hermes (1939), pp. 176-200.

23. Philemon, Lot, and Lycaon, University of California Publications in Classical Philology, 13, No. 4 (Berkeley and Los Angeles: University of California Press, 1945).

24. Fontenrose, p. 119.

25. McGrady, "Un cuento. .." ya cit., p. 145 nota. 